\title{
Postprandial aldosterone inhibition by a sodium-rich mineral water in healthy men and women
}

\author{
L. Toxqui and M. P. Vaquero \\ Institute of Food Science, Technology and Nutrition (ICTAN), Spanish National Research Council (CSIC), ClJosé \\ Antonio Novais 10, 28040 Madrid, Spain
}

Public health promotion policies include the recommendation of reducing sodium/salt intake. The renin-angiotensin-aldosterone system controls electrolyte and water balance and plays a key role against cardiovascular diseases. High aldosterone levels are associated to sodium retention, potassium excretion, hypertension, endothelial dysfunction and heart failure.

A sodium-bicarbonated mineral water has been shown to reduce several markers of cardiovascular risk in adults. Previous findings of our research group showed that its consumption of this water as part of the usual diet reduced LDL-cholesterol ${ }^{(1,2)}$, postprandial lipaemia ${ }^{(3)}$, endothelial dysfunction, and fasting glucose ${ }^{(1)}$ but did not increase blood pressure ${ }^{(1,2)}$. Consistently, aldosterone levels significantly decreased compared to a low mineral water $2 \mathrm{~h}$ after consuming $0.5 \mathrm{~L}$ of such water with a standard meal in postmenopausal women ${ }^{(4)}$. The present study was a 4-way randomized controlled crossover trial designed to investigate the effects of consuming the same sodium-bicarbonated mineral water $(\mathrm{BW})$ with or without a meal, compared to a low mineral content water (CW), on postprandial aldosterone changes.

Twenty-one subjects participated in the study. Inclusion criteria: age $>18$ and $<40$ years and BMI $>18$ and $<30 \mathrm{~kg} / \mathrm{m} 2$. Exclusion criteria: diabetes, hypertension, being a usual consumer of carbonic mineral waters. Two different mineral waters: $\mathrm{BW}\left(\mathrm{HCO}_{3}{ }^{-} 2,120\right.$; $\mathrm{Na}^{+} 1102 ; \mathrm{K}^{+} 49 \cdot 5$; and $\left.\mathrm{Cl}^{-} 597 \mathrm{mg} / \mathrm{L}\right)$ and $\mathrm{CW}\left(\mathrm{HCO}_{3}^{-} 104 ; \mathrm{Na}+8 \cdot 7 ; \mathrm{K}^{+} 2 \cdot 0\right.$; and $\left.\mathrm{Cl}^{-} 11 \mathrm{mg} / \mathrm{L}\right)$ were consumed with or without a standard meal previously detailed ${ }^{(4,5)}$. The trial is register at clinicaltrials.gov as NCT01334840. Aldosterone levels presented significant time $(p<0.001)$ and time $\mathrm{x}$ water interaction $(p<0.05)$, when both waters were consumed with or without the meal. Consumption of BW decreased aldosterone levels at 30,60 and 120 min when consumed alone, and at 120 min when consumed with the meal, compared to CW.

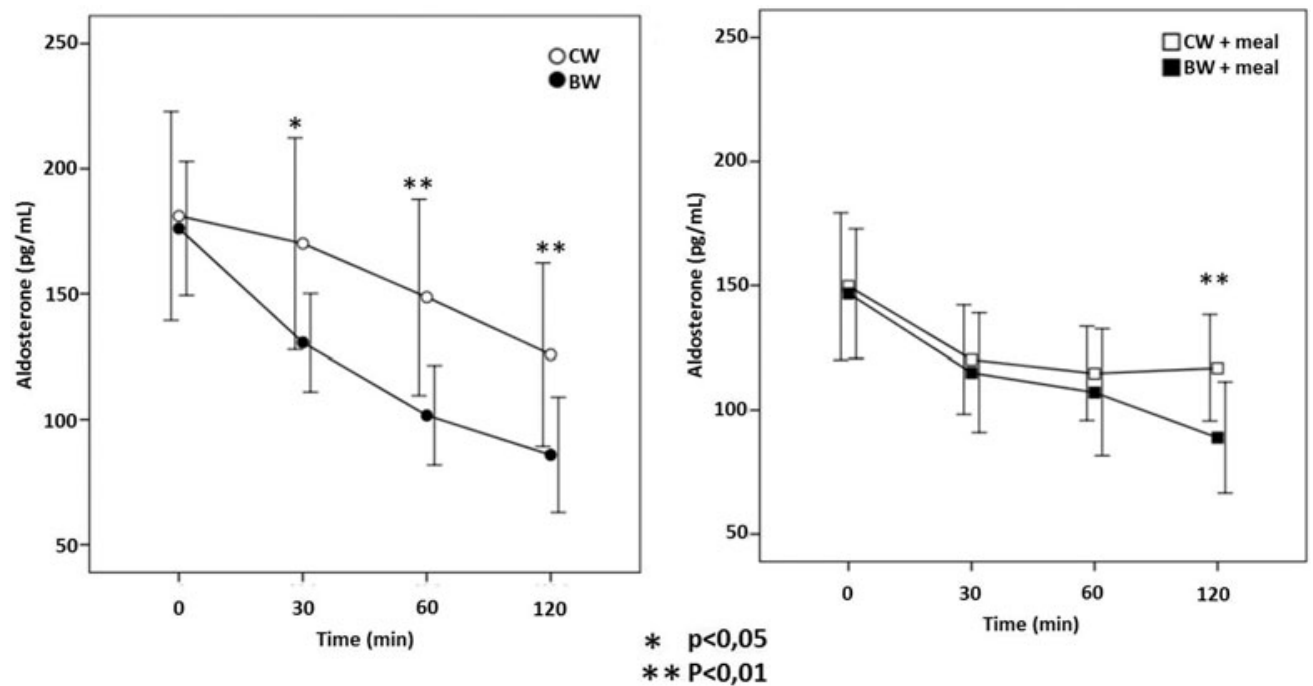

Fig. 1. Postprandial aldosterone levels changes with the consumption of $\mathrm{CW}$ and $\mathrm{BW}$ with or without meal.

These results confirm that this sodium-bicarbonated mineral water induces aldosterone inhibition, either consumed with or without a meal, in healthy adults, and suggest that this physiologic response protects against hypertension.

Study supported by Vichy Catalán, Spain.

1. Schoppen S, Pérez-Granados AM, Carbajal A et al. (2004) J Nutr 134, 1058-1063.

2. Pérez-Granados AM, Navas-Carretero S, Schoppen S et al. (2010) J Nutr Biochem 21, 948-953.

3. Schoppen S, Pérez-Granados AM, Carbajal A et al. (2005) Br J Nutr 94, 582-587.

4. Schoppen S, Pérez-Granados AM, Carbajal A et al. (2008) Int J Food Sci Nutr 59, 347-355.

5. Toxqui L, Pérez-Granados AM, Blanco-Rojo R et al. (2011) Eur J Nutr 51, 607-614. 